\title{
A Natureza Jurídica da Saúde na América Latina e Caribe: um Estudo Constitucional Comparado
}

\author{
LEGAL NATURE OF HEALTH IN LATIN AMERICA AND \\ CARIBEAN: A COMPARED CONSTITUCIONAL STUDY
}

Marina de Neiva Borba $a^{(*)}$
William Saad Hossne $e^{(* *)}$

\section{RESUMO}

Com base na Declaração Universal de Bioética e Direitos Humanos (2005), que reafirma a saúde como direito humano fundamental e como responsabilidade social, este artigo investiga qual a natureza jurídica conferida à saúde pelas Constituições das diferentes regiões da América Latina e Caribe. Utiliza-se o método de pesquisa do estudo constitucional comparado. Conclui-se que: a) o conceito de saúde, quando desenvolvido, funda-se no conceito elaborado pela Organização Mundial de Saúde — OMS (1946); b) a maioria dos países estudados trata a saúde como um direito humano fundamental e como um dever do Estado; c) alguns países consideram-na, ainda, como um dever individual e outros, como bem público.

\section{Palavras-chave}

Direito à Saúde; Estudo Constitucional Comparado; América Latina; Caribe.

\section{ABSTRACT}

Based on the Universal Declaration on Bioethics and Human Rights (2005) that states that health is a fundamental human right, this study aims at

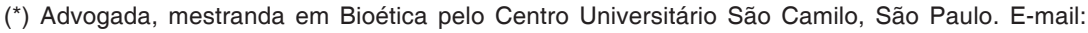
$<$ marinaborba@globo.com>

(**) Médico, professor Titular da Faculdade de Medicina de Botucatu da Universidade Estadual Paulista Júlio de Mesquita Filho, coordenador do Curso de Mestrado em Bioética do Centro Universitário São Camilo, São Paulo. E-mail: <secretariamestrado@saocamilo-sp.br>. Recebido em 15.05.09. Revisado em 09.10.09. Aprovado em 20.12.09. 
investigating how health is expressed in the Constitutions of different regions on Latin America and Caribean. In this research, the description of each constitution is analysed and a comparison is performed. This works concludes that: a) health concept is mainly based on World Health Organization - WHO (1946) description; b) the great majority of the studied countries states that health is indeed a human right and is a duty of the State; c) some countries considered it as an individual duty and others as a public property.

\section{Keywords}

Comparative Constitutional Study; Latin America; Caribean; Right to Health.

\section{INTRODUÇÃO}

No final do século XVIII, a Constituição foi concebida pelos revolucionários norte-americanos e franceses como instrumento para a proteção dos direitos inatos do ser humano e para o reconhecimento da soberania popular. $\mathrm{O}$ artigo 16 da Declaração dos Direitos do Homem e do Cidadão, votada pela Assembléia Nacional Francesa em 4 de agosto de 1789, reproduz esse duplo fundamento de legitimidade: "Toda sociedade, na qual a garantia dos direitos não é assegurada nem a separação dos poderes determinada, não tem Constituição"(1).

A Declaração Universal dos Direitos Humanos, proclamada em 1948 pela Organização das Nações Unidas, também destacou a necessidade de positivação dos direitos humanos por ela reconhecidos: "Considerando ser essencial que os direitos humanos sejam protegidos pelo império da lei, para que o ser humano não seja compelido, como último recurso, à rebelião contra a tirania e a opressão"(2).

Exigiu-se, pois, o reconhecimento técnico desses direitos, mediante a inscrição no texto das Constituições (recurso jurídico denominado de garantias constitucionais dos direitos fundamentais), "visto que as Declarações de Direitos careciam de força e de mecanismos jurídicos que Ihes imprimissem eficácia bastante"(3).

(1) COMPARATO, Fábio Konder. Ética: direito, moral e religião no mundo moderno. São Paulo: Companhia das Letras, 2006. p. 608.

(2) Preâmbulo. ONU. Declaração Universal dos Direitos Humanos. 1948. Disponível em: <http:// www.onu-brasil.org.br/documentos_direitoshumanos.php>. Acesso em: 27 mar. 2009.

(3) SILVA, José Afonso da. Curso de direito constitucional positivo. 24. ed. rev. e atual. São Paulo: Malheiros Ed., 2005. p. 166-167. 
Logo, entendem-se "as normas de direitos humanos como materialmente constitucionais"(4), eis que se incluem no núcleo básico do sistema político da democracia constitucional: a proteção e a promoção da dignidade humana pelo Estado de Direito(5).

Nessa esteira, especificamente quanto ao tratamento jurídico conferido à saúde, Dallari(6) destaca o seu reconhecimento, tardio, como direito fundamental da pessoa humana:

Embora possam ser referidas normas sanitárias nos mais antigos documentos escritos pelo homem, nem mesmo na Declaração dos Direitos dos Homens, adotada pela Organização das Nações Unidas (ONU) (7), em 1948, o direito à saúde é inequivocadamente afirmado. Apenas com a aprovação do Pacto Internacional de Direitos Econômicos, Sociais e Culturais, pela Assembléia Geral da ONU, em 1966, é reconhecido o direito de todas as pessoas ao desfrute do mais alto nível possível de saúde física e mental.

Em 1978, a Declaração de Alma-Ata, aprovada na Conferência Internacional sobre os Cuidados de Saúde Primários, concretizou( ${ }^{(8)}$ a saúde enquanto direito e inovou, ao explicitá-la como responsabilidade/dever, sob a égide da Organização Mundial de Saúde (OMS) e do Fundo Internacional das Nações Unidas para Apoio à Criança (UNICEF):

I) A Conferência enfatiza que a saúde - estado de completo bemestar físico, mental e social, e não simplesmente a ausência de doença ou enfermidade - é um direito humano fundamental, e que a consecução do mais alto nível possível de saúde é a mais importante meta social mundial, cuja realização requer a ação de muitos outros setores sociais e econômicos, além do setor saúde (...)

V) Os governos têm pela saúde de seus povos uma responsabilidade que só pode ser realizada mediante adequadas medidas sanitárias e sociais ${ }^{(9)}$.

(4) WEIS, Carlos. Direitos humanos contemporâneos. 1.ed. São Paulo: Malheiros Ed., 2006. p. 27-28.

(5) "Expressão cunhada pela doutrina germânica de direito público, no final do século XIX, para designar a organização política em que a vontade dos titulares do poder (...) não pode nunca sobrepor-se às normas fundamentais do Estado". COMPARATO, Fábio Konder. op. cit., p. 664 .

(6) DALLARI, Sueli Gandolfi. Book reviews: el derecho a la salud en las Americas: estudio constitucional comparado. Revista de Saúde Pública, São Paulo, v. 22, n. 4, p. 433, 1998.

(7) Artigo XXV: 1. Todo ser humano tem direito a um padrão de vida capaz de assegurar-Ihe, e a sua família, saúde e bem-estar, inclusive alimentação, vestuário, habitação, cuidados médicos e os serviços sociais indispensáveis, e direito à segurança em caso de desemprego, doença, invalidez, viuvez, velhice ou outros casos de perda dos meios de subsistência em circunstâncias fora de seu controle (ONU. Declaração Universal dos Direitos Humanos. 1948, cit. (Grifado).

(8) MOULIN, Madeleine. Saúde (Direito à). In: HOTTOIS, Gilbert; MISSA, Jean-Nöel (Org.) Nova enciclopédia de bioética: medicina, ambiente e tecnologia. Tradução: Maria Carvalho. Portugal: Instituto Piaget, 2003. (Coleção Medicina e Saúde).

(9) OMS. UNICEF. Declaração de Alma-Ata. 1978. Disponível em: < http://www.opas.org.br/coletiva/ uploadArq/Alma-Ata.pdf>. Acesso em: 25 mar. 2009. Grifado. 
Finalmente, a Bioética(10), preocupada em conduzir eticamente os rápidos avanços da ciência e da tecnologia para a consecução dos direitos fundamentais, respeitando a dignidade humana, proclamou a Declaração Universal de Bioética e Direitos Humanos (2005), tratando a saúde tanto como direito, quanto como responsabilidade social/(11).

Verifica-se, portanto, que a natureza jurídica contemporânea da saúde envolve simultaneamente duas concepções ${ }^{(12):}$ direito e dever/responsabilidade.

Dessa forma, ante o status constitucional da saúde, declarada pacificamente como integrante do sistema de direitos humanos, procurou-se analisar qual foi a natureza jurídica conferida à saúde pelas Constituições dos países da América Latina e do Caribe. Como método, realizou-se um estudo constitucional comparado, a partir de uma pesquisa bibliográfica e documental, com natureza qualitativa, para a utilização dos resultados de forma pura, visando à finalidade descritiva.

\section{A CONCEITUAÇÃo de SAÚdE}

Para garantir a proteção e a promoção da saúde, faz-se necessário que o Estado delimite o seu conceito. Assim, primeiramente, averiguar-se-á como a saúde foi conceituada nas Constituições da América Latina e do Caribe.

A definição de saúde mais aceita atualmente é a formulada na introdução da Constituição da Organização Mundial de Saúde - OMS, em 22 de julho de 1948: "a saúde é um estado de completo bem-estar físico, mental e social, que não consiste somente na ausência de doença ou enfermidade" ${ }^{(13)}$.

(10) Como a acepção do direito à saúde é múltipla e o seu uso se torna extenso, Moulin aponta que, para a Bioética, esclarecer esse contributo implica compreender a bioética no sentido quase etimológico de ética da própria vida, em todas as suas expressões e manifestações, e não apenas quando a vida se confronta com ajudas ou suportes provenientes de práticas biomédicas e de sistemas de saúde. MOULIN, Madeleine. op. cit., p. 583.

(11) "Artigo 14 - Responsabilidade Social e Saúde: a) A promoção da saúde e do desenvolvimento social para a sua população é objetivo central dos governos, partilhado por todos os setores da sociedade; b) Considerando que usufruir o mais alto padrão de saúde atingível é um dos direitos fundamentais de todo ser humano, sem distinção de raça, religião, convicção política, condição econômica ou social, o progresso da ciência e da tecnologia deve ampliar: I. O acesso a cuidados de saúde de qualidade e a medicamentos essenciais, incluindo especialmente aqueles para a saúde de mulheres e crianças, uma vez que a saúde é essencial à vida em si e deve ser considerada como um bem social e humano; II. O acesso a nutrição adequada e água de boa qualidade; III. A melhoria das condições de vida e do meio ambiente; IV. A eliminação da marginalização e da exclusão de indivíduos por qualquer que seja o motivo; V. A redução da pobreza e do analfabetismo". UNESCO. Declaração Universal de Bioética e Direitos Humanos. 2005. Tradução de: Ana Tapajós e Mauro Machado do Prado. Disponível em: <http://www.bioetica.catedraunesco.unb.br/htm/X\%20-\%20htm/ documentos/declaracaojulho2006.pdf>. Acesso em: 23 abr. 2009. Grifado.

(12) FUENZALIDA-PUELMA, Hérma L; CONNOR, Susan S. El derecho a la salud em las Americas: estudio constitucional comparado. Washington: Organización Panamericana de la Salud, 1989. p. 631. (13) MOULIN, Madeleine. op. cit., p. 582. 
A Constituição do Panamá(14) (1972) adota esse conceito de saúde postulado pela OMS:

Artículo 105. Es función esencial del Estado velar por la salud de la población de la República. El individuo, como parte de la comunidad, tiene derecho a la promoción, protección, conservación, restitución y rehabilitación de la salud y la obligación de conservarla, entendida ésta como el completo bienestar físico, mental y social. (Grifado).

Em sentido semelhante, as Cartas Constitucionais da Bolívia ${ }^{(15)}$ (1967) e de El Salvador ${ }^{(16)}$ (1983), ao resguardarem a infância, determinam que a proteção da "saúde física, mental e moral" dos menores de idade cabe ao Estado.

Da leitura desses textos constitucionais, constata-se a substituição do vocábulo social por moral. A princípio, deduz-se que cada constituinte tenha priorizado esse atributo específico, em detrimento daquele, por entender mais relevante.

No entanto, as duas assertivas, em diferentes momentos, são igualmente estabelecidas na Constituição da Guatemala(17) (1985):

Art. 51. Protección a menores y ancianos. El Estado protegerá la salud física, mental y moral de los menores de edad y de los ancianos...

Art. 94. Obligación del Estado, sobre salud y asistencia social. El Estado velará por la salud y la asistencia social de todos los habitantes. Desarrollará, a través de sus instituciones, acciones de prevención, promoción, recuperación, reh abilitación, coordinación y las complementarias pertinentes a fin de procurarles el más completo bienestar físico, mental y social. (Grifado).

(14) PANAMÁ. Constituição (1972). Constitución Política de la República de Panamá. Reformada por los Actos Reformatorios N. 1 y N. 2 de 5 y 25 de octubre de 1978, respectivamente; por el Acto Constitucional aprobado el 24 de abril de 1983; por los Actos Legislativos N. 1 de 1993 y N. 2 de 1994; y por el Acto Legislativo N. 1 de 2004. Disponível em: <http://pdba.georgetown.edu/ Constitutions/Panama/constitucion2004.pdf>. Acesso em: 26 mar. 2009.

(15) "Artículo 199. Protección por el Estado de la salud física mental y moral de la infancia: I. El Estado protegerá la salud física, mental y moral de la infancia, y defenderá los derechos del niño al hogar y a la educación" (Grifado) (BOLÍVIA. Constituição (1967). Constitución Política de la República de Bolivia. Con reformas de 1994, texto concordado de 1995, y reformas de 2002, 2004 y 2005. Disponível em: <http://pdba.georgetown.edu/Constitutions/Bolivia/consboliv2005.html>. Acesso em: 26 mar. 2009).

(16) "Artículo 35. El Estado protegerá la salud física, mental y moral de los menores, y garantizará el derecho de éstos a la educación y a la asistencia" (Grifado) (EL SALVADOR. Constituição (1983). Constitucion de la Republica de El Salvador. Con reformas hasta 15 de octubre del 2003 incluídas. Disponível em: <http://pdba.georgetown.edu/Constitutions/EISal/constitucion2003.pdf>. Acesso em: 26 mar. 2009).

(17) GUATEMALA. Constituição (1985). Constitucion Politica de la Republica de Guatemala. Reformada por Acuerdo Legislativo n. 18-93 del 17 de Noviembre de 1993. Disponível em: <http://pdba.georgetown.edu/ Constitutions/Guate/guate93.html>. Acesso em: 26 mar. 2009. 
Nesse caso, observa-se que o bem-estar social perde espaço para o bem-estar moral quando a proteção da saúde está atrelada à infância e/ou ao idoso. Segre e Ferraz ${ }^{(18)}$, ao analisarem o conceito de saúde da OMS, constatam a impropriedade da expressão "perfeito bem-estar social":

Com relação a esse aspecto, Freud (1908 e 1930), em mais de uma oportunidade, procurou mostrar como a perfeita felicidade de um indivíduo dentro da civilização constitui algo impossível. Para ele, a civilização passou a existir quando os homens fizeram um pacto entre si, pelo qual trocaram uma parcela de sua liberdade pulsional por um pouco de segurança. Desta forma, a própria organização social e a condição mesma da existência do homem em grupos baseiam-se em uma renúncia que, ainda que assegure ao indivíduo certos benefícios, gera um constante sentimento de "mal-estar".

Assim, poder-se-ia (equivocadamente) cogitar que a distinção do conceito de Saúde está proporcionalmente relacionada com o mal-estar gerado pela própria civilização e as diferentes situações sócio-culturais de determinados grupos de pessoas.

Como o texto Constitucional do Uruguai ${ }^{(19)}$ (1967) elenca outra forma de conceituação de Saúde (aperfeiçoamento físico, moral e social), retornase ao ponto inicial para sustentar que realmente cada país adota 0 atributo específico mais conveniente.

Não obstante a necessidade de conceituação da saúde, conclui-se, pois, que poucas foram as Constituições Latinas que se preocuparam em conceituá-la: apenas a Bolívia, El Salvador, Guatemala, Panamá e Uruguai. Além disso, constata-se que esses países se basearam no conceito da OMS (1948) formulado anteriormente à promulgação das suas Constituições.

\section{A NATUREZA JURÍDICA DA SAÚDE}

Como visto, a concepção contemporânea de saúde está assentada num duplo e simultâneo tratamento jurídico: o seu reconhecimento técnico como direito e como dever/responsabilidade.

(18) SEGRE, Marcos; FERRAZ, Flávio Carvalho. O conceito de saúde. Revista de Saúde Pública, São Paulo, v. 31, n. 5, p. 538-542, 1997. Disponível em: <http://www.scielo.br/pdf/rsp/v31n5/ 2334.pdf>. Acesso em: 27 mar. 2009.

(19) "Art. 44. El Estado legislará en todas las cuestiones relacionadas con la salud e higiene públicas, procurando el perfeccionamiento físico, moral y social de todos los habitantes del país. Todos los habitantes tienen el deber de cuidar su salud, así como el de asistirse en caso de enfermedad. El Estado proporcionará gratuitamente los medios de prevención y de asistencia tan sólo a los indigentes o carentes de recursos suficientes" (Grifado) (URUGUAI. Constituição (1967). Constitución Política de la República Oriental del Uruguay. Incluye reformas plebiscitadas el 26 de Noviembre de 1989; 26 de Noviembre de 1994; 8 de Diciembre de 1996 y 31 de Octubre de 2004. Disponível em: <http:// pdba.georgetown.edu/Constitutions/Uruguay/uruguay04.html>. Acesso em: 26 mar. 2009). 
Fuenzalida-Puelma e Connor ${ }^{(20)}$ apresentam os desdobramentos dessa "bipositivação": a saúde pode ser considerada como um direito individual e social:

A expectativa e a possibilidade de ter acesso aos serviços de saúde público ou privados, para atenção ou tratamento, caracterizam a saúde como direito individual (...) O direito à saúde pode ser visto como um direito eminentemente social enquanto corresponde a toda comunidade e, portanto, requer atenção por parte da sociedade organizada. (Grifado)

Concomitantemente, a saúde figura-se como um triplo dever, à medida que a responsabilidade pela sua garantia compete tanto ao indivíduo e a família, como à comunidade e ao Estado:

O cuidado com a saúde pessoal e familiar é um dever que obriga o indivíduo a tomar as medidas necessárias ao respeito à sua vida e seu aperfeiçoamento pessoal e do grupo familiar (...)

É obrigação do conjunto de indivíduos cooperar amplamente com seus semelhantes e com a comunidade de que são parte, em sua preservação e manutenção. Esta relação com os demais deve ser presidida pela idéia de solidariedade que, como tal, conserva o respeito do homem pelo homem em sua pessoa e seus direitos

Ao Estado compete à responsabilidade pelo fomento e proteção da saúde em termos de ações concretas, tanto em seu caráter de representante dos indivíduos no coletivo social, como de árbitro das relações dos indivíduos, por si, ou como integrantes de um estrato ou grupo de pressão ou interesses. ${ }^{(21)}$

Em decorrência da preocupação com a implementação dos direitos humanos, tem-se percebido que os avanços legislativos só podem ser alcançados se houver um duplo objetivo nas novas declarações e tratados: "especificar os direitos consagrados nos pactos internacionais e criar mecanismos que garantam a sua eficácia tanto na proteção quanto na promoção dos direitos atribuídos, sempre tendo no horizonte a complementaridade dos direitos humanos"(22).

Para a garantia da saúde, portanto, torna-se necessário ratificá-la, ao mesmo tempo, como um direito e como um dever. Dallari(23) corrobora:

(20) FUENZALIDA-PUELMA, Herma L; Connor, Susan S. op. cit., p. 630.

(21) Id., loc. cit.

(22) WEIS, Carlos. op. cit., p. 59.

(23) DALLARI, Sueli Gandolfi. Uma nova disciplina: o direito sanitário. Revista de Saúde Pública, São Paulo, v. 22, n. 4, 1988. p. 330. Disponível em: <http://www.scielo.br/pdf/rsp/v22n4/08.pdf>. Acesso em: 30 mar. 2009. 
Atualmente, a saúde não tem apenas um aspecto individual que respeita apenas a pessoa. Não basta que sejam colocados à disposição dos indivíduos todos os meios para promoção, manutenção ou recuperação da saúde para que o Estado responda satisfatoriamente à obrigação de garantir a saúde do povo. Hoje os Estados são, em sua maioria, forçados por disposição constitucional a proteger a saúde contra todos os perigos. Até mesmo contra a irresponsabilidade de seus próprios cidadãos. A saúde "pública" tem um caráter coletivo. $O$ Estado contemporâneo controla o comportamento dos indivíduos no intuito de impedir-lhes qualquer ação nociva à saúde de todo o povo. E o faz por meio de leis. É a própria sociedade por decorrência lógica que define quais são esses comportamentos nocivos e determina que eles sejam evitados, que seja punido o infrator e qual a pena que deve ser-Ihe aplicada. Tal atividade social é expressa em leis que a administração pública deve cumprir e fazer cumprir.

Resta verificar, comparativamente, como as Constituições dos países Latino-Americanos e Caribenhos reconheceram tal bem jurídico.

\section{Saúde como Direito}

A saúde é considerada como direito subjetivo(24), "na medida em que permite que o cidadão ingresse com uma ação junto ao Poder Judiciário para exigir do Estado (...) a adoção ou a abstenção de medidas concretas em favor da [sua] saúde"(25). Por outro lado, também assume contornos de direito social, por refletir pretensões coletivas perante o Estado, como a construção de hospitais, etc.

Moulin(26) expõe a problemática dessa dicotomia do direito à saúde. Weis ${ }^{(27)}$ encerra o debate, ressaltando a indivisibilidade e a interdependência dos direitos humanos considerados em espécie: "um certo direito não alcança a eficácia plena sem a realização simultânea de alguns ou de todos os outros direitos humanos".

Assim, verifica-se que os seguintes países consagram explicitamente a saúde como direito nas suas Cartas Constitucionais:

(24) Entende-se como Direito subjetivo o poder que "capacita o indivíduo [integrante da sociedade] a obter o reconhecimento social [jurídico] na esfera do objeto pretendido, desde que o seu ato de vontade possa ser considerado deliberadamente legítimo pelo direito objetivo [positivado]". DUGUIT, León. Fundamentos do direito. São Paulo: Ícone, 2006. p. 7-8. (Coleção Fundamentos do Direito). (25) AITH, Fernando Mussa Abujamra. Teoria geral do direito sanitário brasileiro. São Paulo, USP, 2006. Tese (Doutorado em Saúde Pública). Faculdade de Saúde Pública, Universidade de São Paulo, São Paulo, 2006. p. 92.

(26) MOULIN, Madeleine. op. cit., p. 583.

(27) WEIS, Carlos. op. cit., p. 118. 
BOLÍVIA: Art. 7ํ. Toda persona tiene los siguientes derechos fundamentales (...): a) A la vida, la salud, la seguridad e integridad física y moral y el libre desarrollo de la personalidad.(28)

BRASIL: Art. 6․ São direitos sociais a educação, a saúde, o trabalho, a moradia, o lazer, a segurança, a previdência social, a proteção à maternidade e à infância, a assistência aos desamparados, na forma desta Constituição (...)

Art. 196. A saúde é direito de todos e dever do Estado, garantido mediante políticas sociais e econômicas que visem à redução do risco de doença e de outros agravos e ao acesso universal e igualitário às ações e serviços para sua promoção, proteção e recuperação. ${ }^{(29)}$

CHILE: Art. 19. La Constitución asegura a todas las personas: (...)

9. El derecho a la protección de la salud.(30)

CUBA: Art. 50. Todos tienen derecho a que se atienda y proteja su salud (...).(31)

EQUADOR: Art. 66. Se reconoce y garantizará a las personas: (...)

2. El derecho a una vida digna, que asegure la salud, alimentación y nutrición, agua potable, vivienda, saneamiento ambiental, educación, trabajo, empleo, descanso y ocio, cultura física, vestido, seguridad social $y$ otros servicios sociales necesarios. ${ }^{(32)}$

GUATEMALA: Art. 93. Derecho a la salud. El goce de la salud es derecho fundamental del ser humano, sin discriminación alguna. ${ }^{(33)}$

HONDURAS: Art. 145. Se reconoce el derecho a la protección de la salud. El deber de todos participar en la promoción y preservación de la salud personal y de la comunidad. El Estado conservará el medio ambiente adecuado para proteger la salud de las personas. ${ }^{(34)}$

(28) BOLÍVIA. Constituição (1967). op. cit.

(29) BRASIL. Constituição (1988). Constituição da República Federativa do Brasil. Atualizada até a Emenda Constitucional n. 57, de 18 de dezembro de 2008. Disponível em: <http://www.planalto.gov.br/ ccivil_03/constituicao/Constituiçao_Compilado.htm>. Acesso em: 26 mar. 2009.

(30) CHILE. Constituição (1980). Constitución Política de la República de Chile. Incluye Reformas de 1989, 1991, 1997, 1999, 2000, 2003 y 2005. Disponível em: <http://pdba.georgetown.edu/ Constitutions/Chile/chile05.html>. Acesso em: 26 mar. 2009.

(31) CUBA. Constituição (1976). Constitución Política de la República de Cuba. Actualizada hasta la Ley de Reforma Constitucional 2002. Disponível em: <http://pdba.georgetown.edu/Constitutions/ Cuba/cuba2002.html>. Acesso em: 26 mar. 2009.

(32) EQUADOR. Constituição (2008). Constitución de la República del Ecuador. Disponível em: <http://pdba.georgetown.edu/Constitutions/Ecuador/ecuador08.html\#mozTocld273089>. Acesso em: 26 mar. 2009.

(33) GUATEMALA. Constituição (1985). op. cit.

(34) HONDURAS. Constituição (1982). Constitucion Politica de la Republica de Honduras. Incluye Reformas de 1982, 1984, 1985, 1986, 1987, 1988, 1989, 1990, 1991, 1993, 1994, 1995, 1996, 1997, 1998, 1999, 2000, 2001, 2002, 2003, 2004 y 2005. Disponível em: <http://pdba.georgetown.edu/ Constitutions/Honduras/hond05.html>. Acesso em: 26 mar. 2009. 
MÉXICO: Art. 4‥ El varón y la mujer son iguales ante la ley (...)

Toda persona tiene derecho a la protección de la salud. La ley definirá las bases y modalidades para el acceso a los servicios de salud y establecerá la concurrencia de la Federación y las entidades federativas en materia de salubridad general, conforme a lo que dispone la fracción XVI del artículo 73 de esta Constitución. ${ }^{(35)}$

NICARAGUA: Art. 59. Los nicaraguenses tienen derecho, por igual, a la salud (...).(36)

PANAMÁ: Art. 105. Es función esencial del Estado velar por la salud de la población de la República. El individuo, como parte de la comunidad, tiene derecho a la promoción, protección, conservación, restitución y rehabilitación de la salud y la obligación de conservarla, entendida ésta como el completo bienestar físico, mental y social". (37)

PARAGUAI: Art. 68. DEL DERECHO A LA SALUD. El Estado protegerá y promoverá la salud como derecho fundamental de la persona y en interés de la comunidad (...). ${ }^{\left({ }^{(3)}\right.}$

PERU: Art. 7ํ. Todos tienen derecho a la protección de su salud, la del medio familiar y de la comunidad así como el deber de contribuir a su promoción y defensa (....).(39)

VENEZUELA: Art. 83. La salud es un derecho social fundamental, obligación del Estado, que lo garantizará como parte del derecho a la vida. El Estado promoverá y desarrollará políticas orientadas a elevar la calidad de vida, el bienestar colectivo y el acceso a los servicios. Todas las personas tienen derecho a la protección de la salud, así como el deber de participar activamente en su promoción y defensa, y el de cumplir con las medidas sanitarias y de saneamiento que establezca la ley, de conformidad con los tratados y convenios internacionales suscritos y ratificados por la República. ${ }^{(40)}$

(35) MEXICO. Constituição (1917). Constitución Política de los Estados Unidos Mexicanos. Con las reformas de 1993, 1999, 2000 y 2008. Disponível em: <http://pdba.georgetown.edu/Constitutions/ Mexico/textovigente2008.pdf>. Acesso em: 26 mar. 2009.

(36) NICARAGUA. Constituição (1987). Constitución Política de la República de Nicaragua. Con las reformas de 1995, 2000 y 2005. Disponível em: <http://pdba.georgetown.edu/Constitutions/Nica/ nica05.html>. Acesso em: 26 mar. 2009.

(37) PANAMÁ. Constituição (1972). op. cit.

(38) PARAGUAI. Constituição (1992). Constitución Política de la República de Paraguay. Disponível em: <http://pdba.georgetown.edu/Constitutions/Paraguay/para1992.html>. Acesso em: 26 mar. 2009. (39) PERU. Constituição (1993). Constitución Política del Perú. Con las reformas de 1995, 2000, 2002, 2004 y 2005 (hasta octubre). Disponível em: <http://pdba.georgetown.edu/Constitutions/ Peru/per93reforms05.html>. Acesso em: 26 mar. 2009.

(40) VENEZUELA. Constituição (1999). Constitución de la República Bolivariana de Venezuela. Disponível em: < http://pdba.georgetown.edu/Constitutions/Venezuela/venezuela.html>. Acesso em: 26 mar. 2009. 
A Argentina ${ }^{(41)}$ e a Costa Rica ${ }^{(42)}$ reconhecem o direito à saúde, apenas, aos trabalhadores contribuintes do sistema previdenciário:

ARGENTINA: Art. 42 - Los consumidores y usuarios de bienes y servicios tienen derecho, en la relación de consumo, a la protección de su salud, seguridad e intereses económicos; a una información adecuada y veraz; a la libertad de elección, y a condiciones de trato equitativo y digno.

COSTA RICA: Art. 46. (...) Los consumidores y usuarios tienen derecho a la protección de su salud, ambiente, seguridad e intereses económicos, a recibir información adecuada y veraz; a la libertad de elección, y a un trato equitativo. El Estado apoyará los organismos que ellos constituyan para la defensa de sus derechos. La ley regulará esas materias.

Já a Colômbia ${ }^{(43)}$ reconhece o direito subjetivo universal à saúde somente aos menores de idade:

Art. 44. Son derechos fundamentales de los niños: la vida, la integridad física, la salud y la seguridad social, la alimentación equilibrada, su nombre y nacionalidad, tener una familia y no ser separados de ella, el ciudado y el amor, la educación y la cultura, la recreación y la libre expresión de su opinión. Serán protegidos contra toda forma de abandono, violencia física o moral, secuestro, venta, abuso sexual, explotación laboral o económica y trabajos riesgosos. Gozarán también de los demá derechos consagrados en la Constitiución, en las leyes y en los trados internacionales ratificados por Colombia.

Ampliando-se a interpretação do dispositivo constitucional da República Dominicana ${ }^{(44)}$, também se poderia reconhecer, de uma forma geral, os direitos da pessoa humana:

Art. $8^{\circ}$. Se reconoce como finalidad principal del Estado la protección efectiva de los derechos de la persona humana y el mantenimiento de los medios que le permitan perfeccionarse progresivamente dentro de un orden de libertad individual y de justicia social, compatible con el orden público, el bienestar general y los derechos de todos.

(41) ARGENTINA. Constituição (1994). Constitución Nacional de la República Argentina. Disponível em: <http://pdba.georgetown.edu/Constitutions/Argentina/argen94.html>. Acesso em: 26 mar. 2009. (42) COSTA RICA. Constituição (1949). Constitucion Politica de la Republica de Costa Rica. Incluye Reformas de 1954, 1956, 1957, 1958, 1959, 1961, 1963, 1965, 1968, 1969, 1971, 1975, 1977, 1981, 1982, 1984, 1987, 1989, 1993, 1994, 1995, 1996, 1997, 1999, 2000, 2001, 2002 y 2003. Disponível em: <http://pdba.georgetown.edu/Constitutions/Costa/costa2.html>. Acesso em: 26 mar. 2009.

(43) COLÔMBIA. Constituição (1991). Constitución Política de la República de Colombia. Incluye las reformas de 1993, 1995, 1996, 1997, 1999, 2000, 2001, 2002, 2003, 2004 y 2005. Disponível em: <http://pdba.georgetown.edu/Constitutions/Colombia/col91.html>. Acesso em: 26 mar. 2009.

(44) REPÚBLICA DOMINICANA. Constituição (2002). Constitucion Politica de la Republica Dominicana. Disponível em: < http://pdba.georgetown.edu/Constitutions/DomRep/domrep02.html>. Acesso em: 26 mar. 2009. 
Por fim, conclui-se que a grande maioria dos países estudados reconhece o direito à saúde de forma integral. Apenas quatro países, parcialmente: a Nicarágua, somente aos nicaragüenses; a Argentina e a Costa Rica, aos usuários do sistema previdenciário; e, a Colômbia, aos menores de idade. A República Dominicana, El Salvador e Uruguai não consagraram explicitamente o direito à saúde nas suas Constituições.

\section{Saúde como Dever}

A saúde, enquanto responsabilidade social, constitui-se como um dever de agir. Trata-se, pois, de uma obrigação positiva a ser desempenhada, conjuntamente, pelo indivíduo ou família, pela comunidade e pelo Estado para a proteção e a promoção da saúde.

Todos os textos constitucionais investigados determinaram explicitamente a consecução da saúde como dever do Estado, mediante a implantação de políticas públicas:

BOLívIA: Art. 158. El Estado tiene la obligación de defender el capital humano protegiendo la salud de la población (....).(45)

BRASIL: Art. 196. A saúde é direito de todos e dever do Estado, garantido mediante políticas sociais e econômicas que visem à redução do risco de doença e de outros agravos e ao acesso universal e igualitário às ações e serviços para sua promoção, proteção e recuperação. ${ }^{(46)}$

CHILE: Art. 19. (...) 9. (...) El Estado protege el libre e igualitario acceso a las acciones de promoción, protección y recuperación de la salud y de rehabilitación del individuo. ${ }^{(47)}$

COLÔMBIA: Art. 49. La atención de la salud y el saneamiento ambiental son servicios públicos a cargo del Estado (...)".(48)

CUBA: Art. 50. Todos tienen derecho a que se atienda y proteja su salud. El Estado garantiza este derecho. ${ }^{(49)}$

EQUADOR: Art. 3‥ Son deberes primordiales del Estado:

1. Garantizar sin discriminación alguna el efectivo goce de los derechos establecidos en la Constitución y en los instrumentos internacionales, en particular la educación, la salud, la alimentación, la seguridad social y el agua para sus habitantes. ${ }^{(50)}$

\footnotetext{
(45) BOLÍVIA. Constituição (1967). op. cit.

(46) BRASIL. Constituição (1988). op. cit.

(47) CHILE. Constituição (1980). op. cit.

(48) COLÔMBIA. Constituição (1991). op. cit.

(49) CUBA. Constituição (1976). op. cit.

(50) EQUADOR. Constituição (2008). op. cit.
} 
EL SALVADOR: Art. 1… (..) Es obligación del Estado asegurar a los habitantes de la República, el goce de la libertad, la salud, la cultura, el bienestar económico y la justicia social.(51)

GUATEMALA: Art. 94. Obligación del Estado, sobre salud y asistencia social. El Estado velará por la salud y la asistencia social de todos los habitantes. Desarrollará, a través de sus instituciones, acciones de prevención, promoción, recuperación, reh abilitación, coordinación y las complementarias pertinentes a fin de procurarles el más completo bienestar físico, mental y social. ${ }^{(52)}$

HONDURAS: Art. 145. Se reconoce el derecho a la protección de la salud. El deber de todos participar en la promoción y preservación de la salud personal y de la comunidad. El Estado conservará el medio ambiente adecuado para proteger la salud de las personas. ${ }^{(53)}$

NICARAGUA: Art. 105. (...) Los servicios de educación, salud y seguridad social, son deberes indeclinables del Estado, que está obligado a prestarlos sin exclusiones, a mejorarlos y ampliarlos. Las instalaciones e infraestructura de dichos servicios propiedad del Estado, no pueden ser enajenados bajo ninguna modalidad (...).(54)

PANAMÁ: Art. 105. Es función esencial del Estado velar por la salud de la población de la República. El individuo, como parte de la comunidad, tiene derecho a la promoción, protección, conservación, restitución y rehabilitación de la salud y la obligación de conservarla, entendida ésta como el completo bienestar físico, mental y social. ${ }^{(55)}$

PARAGUAI: Artículo 68. DEL DERECHO A LA SALUD. El Estado protegerá y promoverá la salud como derecho fundamental de la persona y en interés de la comunidad (...).(56)

PERU: Art. 9․ El Estado determina la política nacional de salud. El Poder Ejecutivo norma y supervisa su aplicación. Es responsable de diseñarla y conducirla en forma plural y descentralizadora para facilitar a todos el acceso equitativo a los servicios de salud (...)

Art. 11. El Estado garantiza el libre acceso a prestaciones de salud y a pensiones, a través de entidades públicas, privadas o mixtas. Supervisa asimismo su eficaz funcionamiento. ${ }^{(57)}$

REPÚBLICA DOMINICANA: Art. $8^{\circ}$. Se reconoce como finalidad principal del Estado la protección efectiva de los derechos de la persona

(51) EL SALVADOR. Constituição (1983). op. cit.

(52) GUATEMALA. Constituição (1985). op. cit.

(53) HONDURAS. Constituição (1982). op. cit.

(54) NICARAGUA. Constituição (1987). op. cit.

(55) PANAMÁ. Constituição (1972). op. cit.

(56) PARAGUAI. Constituição (1992). op. cit.

(57) PERU. Constituição (1993). op. cit. 
humana y el mantenimiento de los medios que le permitan perfeccionarse progresivamente dentro de un orden de libertad individual y de justicia social, compatible con el orden público, el bienestar general y los derechos de todos. ${ }^{(58)}$

VENEZUELA: Art. 83. La salud es un derecho social fundamental, obligación del Estado, que lo garantizará como parte del derecho a la vida. ${ }^{(59)}$

Vale ressaltar que, na Argentina ${ }^{(60)}$ e na Costa Rica ${ }^{(61)}$, tal responsabilidade foi limitada apenas aos usuários filiados ao sistema previdenciário:

ARGENTINA: Art. 42. Los consumidores y usuarios de bienes y servicios tienen derecho, en la relación de consumo, a la protección de su salud, seguridad e intereses económicos; a una información adecuada y veraz; a la libertad de elección, y a condiciones de trato equitativo y digno.

Las autoridades proveerán a la protección de esos derechos, a la educación para el consumo, a la defensa de la competencia contra toda forma de distorsión de los mercados, al control de los monopolios naturales y legales, al de la calidad y eficiencia de los servicios públicos, y a la constitución de asociaciones de consumidores y de usuários.

COSTA RICA: Art. 46. (...) Los consumidores y usuarios tienen derecho a la protección de su salud, ambiente, seguridad e intereses económicos, a recibir información adecuada y veraz; a la libertad de elección, y a un trato equitativo. El Estado apoyará los organismos que ellos constituyan para la defensa de sus derechos. La ley regulará esas materias.

Ademais, o México(62) restringiu o dever de promoção integral da saúde pelo Estado somente aos povos indígenas e às crianças; e o Uruguai(63), aos carentes de recursos:

MÉXICO: Art. 2-B. Para abatir las carencias y rezagos que afectan a los pueblos y comunidades indígenas, dichas autoridades, tienen la obligación de: (...) III. Asegurar el acceso efectivo a los servicios de salud mediante la ampliación de la cobertura del sistema nacional, aprovechando debidamente la medicina tradicional, así como apoyar la nutrición de los indígenas mediante programas de alimentación, en especial para la población infantil (...)

Art. 4․ El varón y la mujer son iguales ante la ley (...) Los niños y las niñas tienen derecho a la satisfacción de sus necesidades de alimentación, salud, educación y sano esparcimiento para su desarrollo integral...

(58) REPÚBLICA DOMINICANA. Constituição (2002). op. cit.

(59) VENEZUELA. Constituição (1999). op. cit.

(60) ARGENTINA. Constituição (1994). op. cit.

(61) COSTA RICA. Constituição (1949). op. cit.

(62) MEXICO. Constituição (1917). op. cit.

(63) URUGUAI. Constituição (1967). op. cit. 
URUGUAI: Art. 44. (...) Todos los habitantes tienen el deber de cuidar su salud, así como el de asistirse en caso de enfermedad. El Estado proporcionará gratuitamente los medios de prevención y de asistencia tan sólo a los indigentes o carentes de recursos suficientes.

Não satisfeitos com a consagração da saúde como dever do Estado, a Colômbia( ${ }^{(64)}$, El Salvador ${ }^{(65)}$, Guatemala ${ }^{(66)}$, Honduras ${ }^{(67)}$, Panamá(68), Paraguai ${ }^{(69)}$, Peru( ${ }^{(70)}$, Uruguai( ${ }^{(71)}$ e Venezuela ${ }^{(72)}$ ainda estipularam-na como dever individual.

Imperioso destacar que, em alguns textos, o dever da pessoa de cuidar da sua saúde recebeu o status de obrigação de cumprimento das medidas sanitárias impostas pela lei, como a Constituição Paraguaia.

Conclui-se, pois, que todos os países Latinos reconheceram a proteção e a promoção da saúde como dever do Estado. Contudo, quatro deles

(64) "Art. 49. (...) Toda persona tiene el deber de procurar el cuidado integral de su salud y la de su comunidad" (COLÔMBIA. Constituição (1991). op. cit.

(65) EL SALVADOR: "Art. 65. La salud de los habitantes de la República constituye un bien público. El Estado y las personas están obligadas a velar por su conservación y restablecimiento. El Estado determinará la política nacional de salud y controlará y supervisará su aplicación". EL SALVADOR. Constituição (1983). op. cit.

(66) "Art. 95. La salud, bien público. La salud de los habitantes de la Nación es un bien público. Todas las personas e instituciones están obligadas a velar por su conservación y restablecimiento" (GUATEMALA. Constituição (1985). op. cit.).

(67) "Art. 145. Se reconoce el derecho a la protección de la salud. El deber de todos participar en la promoción y preservación de la salud personal y de la comunidad. El Estado conservará el medio ambiente adecuado para proteger la salud de las personas" (HONDURAS. Constituição (1982). op. cit.).

(68) "Art. 105. Es función esencial del Estado velar por la salud de la población de la República. El individuo, como parte de la comunidad, tiene derecho a la promoción, protección, conservación, restitución y rehabilitación de la salud y la obligación de conservarla, entendida ésta como el completo bienestar físico, mental y social" (PANAMÁ. Constituição (1972). op. cit.).

(69) "Artículo 68. DEL DERECHO A LA SALUD. (...) Toda persona está obligada a someterse a las medidas sanitarias que establezca la ley, dentro del respeto a la dignidad humana" (PARAGUAI. Constituição (1992). op. cit.).

(70) "Artículo 7. Todos tienen derecho a la protección de su salud, la del medio familiar y de la comunidad así como el deber de contribuir a su promoción y defensa. La persona incapacitada para valor por sí misma a causa de una deficiencia física o mental tiene derecho al respeto de su dignidad y a un régimen legal de protección, atención, readaptación y seguridad. (PERÚ. Constituição (1993). op. cit.).

(71) URUGUAI: "Art. 44. El Estado legislará en todas las cuestiones relacionadas con la salud e higiene públicas, prourando el perfeccionamiento físico, moral y social de todos los habitantes del país. Todos los habitantes tienen el deber de cuidar su salud, así como el de asistirse en caso de enfermedad. El Estado proporcionará gratuitamente los medios de prevención y de asistencia tan sólo a los indigentes o carentes de recursos suficientes". URUGUAI. Constituição (1967). op. cit. (72) "Artículo 83. La salud es un derecho social fundamental, obligación del Estado, que lo garantizará como parte del derecho a la vida. El Estado promoverá y desarrollará políticas orientadas a elevar la calidad de vida, el bienestar colectivo y el acceso a los servicios. Todas las personas tienen derecho a la protección de la salud, así como el deber de participar activamente en su promoción y defensa, y el de cumplir con las medidas sanitarias y de saneamiento que establezca la ley, de conformidad con los tratados y convenios internacionales suscritos y ratificados por la República" (VENEZUELA. Constituição (1999). op. cit.). 
limitaram à sua garantia: na Argentina e na Costa Rica, aos trabalhadores filiados à previdência; no México, às crianças e aos povos indígenas; e, no Uruguai, aos carentes de recursos. Nove ainda acrescentaram a responsabilidade pessoal.

\section{Saúde como Bem Público}

Curiosamente, encontrou-se outra forma jurídica de identificação da saúde: como bem público. A partir da sua definição ${ }^{(73)}$, infere-se o enfoque patrimonial dado a esse instituto e a conseqüente vinculação ao interesse coletivo.

Nessa esteira, compreende-se que toda produção de serviços de saúde, inclusive de cunho privado, deve estar pautada na defesa radical da vida individual e coletiva, em detrimento de qualquer bem de mercado(74).

Foram duas as Constituições que prescreveram a saúde dessa forma:

EL SALVADOR: Artículo 65. La salud de los habitantes de la República constituye un bien público. El Estado y las personas están obligados a velar por su conservación y restablecimiento. El Estado determinará la política nacional de salud y controlará y supervisará su aplicación. ${ }^{(75)}$

GUATEMALA: Artículo 95. La salud, bien público. La salud de los habitantes de la Nación es un bien público. Todas las personas e instituciones están obligadas a velar por su conservación y restablecimiento. ${ }^{(76)}$

Verifica-se, pois, que a conservação da saúde, em El Salvador e na Guatemala, constitui responsabilidade tanto do Estado como das próprias pessoas.

\section{CONSIDERAÇÕES FINAIS}

Embora tenha a natureza jurídica de direito humano fundamental e de responsabilidade social, conforme pacificado pela Declaração Universal de Bioética e Direitos Humanos, verificou-se que a saúde não recebe um tratamento constitucional uniforme nas diferentes regiões da América Latina e Caribe, concluindo-se que:

(73) "Bem público - é um bem econômico consumido e custeado de forma coletiva". HOLANDA, Aurélio Buarque de. Bem público. In: Novo dicionário Aurélio da língua portuguesa. 3. ed. rev. e atual. São Paulo: Ed. Positivo, 2004.

(74) MERHY, Emerson Elias. Fórum Social Mundial e a Saúde: por uma ética global da vida. Interface, Botucatu, v. 6, n. 11, ago. 2002. Disponível em: <http://www.scielo.br/scielo.php?script=sci_arttext\&pid=S1414328 $32002000200016 \& \operatorname{lng}=e n \& n r m=i s o>$. Acesso em: 06 out. 2009.

(75) EL SALVADOR. Constituição (1983). op. cit.

(76) GUATEMALA. Constituição (1985). op. cit. 
1. Apenas a Bolívia, El Salvador, Guatemala, Panamá e Uruguai preocuparam-se em explicitar constitucionalmente o conceito de Saúde. Além disso, esses países basearam-se na conceituação da OMS, em 1948, formulada anteriormente à promulgação das suas Constituições. Dessa forma, não se pode afirmar que há plena uniformidade conceitual entre esses países, tendo em vista as peculiares adotadas em cada Carta Constitucional.

2. Os textos constitucionais dos países da América Latina e Caribe estudados tratam a Saúde como:

a. Direito: A grande maioria dos países estudados reconheceu a saúde como direito subjetivo de todo homem e/ou como direito social. Entretanto, a Nicarágua restringiu o direito subjetivo apenas aos nicaraguenses; a Argentina e a Costa Rica, aos usuários do sistema previdenciário; e, a Colômbia, aos menores de idade. Por sua vez, a República Dominicana destacou os direitos da pessoa humana de uma forma ampliativa, supondo-se a inclusão desse direito. Somente EI Salvador e Uruguai não consagram o direito à saúde.

b. Dever. Todos os países vislumbraram a proteção e a promoção da saúde como dever do Estado. Contudo, quatro deles limitaram à sua garantia: na Argentina e na Costa Rica, aos trabalhadores filiados à previdência; no México, às crianças e aos povos indígenas; e, no Uruguai, aos carentes de recursos. Vale ressaltar que Colômbia, El Salvador, Guatemala, Honduras, Panamá, Paraguai, Peru, Uruguai e Venezuela ainda destacaram a saúde como dever individual.

c. Direito, Dever Estatal e Dever Individual: Além da consagração da saúde como direito subjetivo e como responsabilidade do Estado, a Colômbia, Guatemala, Honduras, Panamá, Paraguai, Peru e Venezuela ainda estipularam a Saúde como dever de todo homem.

d. Dever Estatal e Dever Individual: As Cartas Constitucionais de El Salvador e do Uruguai definiram a Saúde tão-somente como responsabilidade do Estado e da pessoa.

e. Bem público: El Salvador e Guatemala consideraram a Saúde como patrimônio individual e coletivo da sociedade. Conseqüentemente, obrigaram a conservação da Saúde pelo Estado e pelas próprias pessoas.

Necessário esclarecer que, embora não haja o tratamento jurídico explícito da saúde na Constituição, a Argentina recepcionou várias Convenções sobre Direitos Humanos com status constitucional, em especial o "Pacto Internacional de Derechos Económicos, Sociales y Culturales y Observación General 14/2000 del Comité PIDESC: 'El derecho al disfrute del más alto nível posible de salud'"(77).

(77) MAINETTI, José Alberto; PÉREZ, Marta Lucía. Referenciais de bioética en Argentina. In: PESSINI, Leo et al. (Coord.). Perspectivas de la bioética en Iberoamérica. Chile: OPS/OMS, 2007. p. 71-75. 
Finalmente, pode-se afirmar que, majoritariamente, as Constituições da América Latina e do Caribe reconhecem a saúde enquanto direito e dever. Entretanto, constata-se uma variedade de enfoques que refletem uma profunda diferença em matéria de filosofia política. Conseqüentemente, o tratamento constitucional conferido à saúde traduz-se na maneira em que o Estado entende e assume a sua responsabilidade em relação à saúde dos habitantes.

\section{REFERÊNCIAS BIBLIOGRÁFICAS}

AITH, Fernando Mussa Abujamra. Teoria geral do direito sanitário brasileiro. São Paulo, USP, 2006. Tese (Doutorado em Saúde Pública). Faculdade de Saúde Pública, Universidade de São Paulo, São Paulo, 2006.

ARGENTINA. Constituição (1994). Constitución Nacional de la República Argentina. Disponível em: <http://pdba.georgetown.edu/Constitutions/ Argentina/argen94.html>. Acesso em: 26 mar. 2009.

BASE de Datos Políticos de las Américas. (2006) Salud, vivienda y alimentación. Estudio Constitucional Comparativo. [Internet]. Centro de Estudios Latinoamericanos, Escuela de Servicio Exterior, Universidad de Georgetown. En: <http://pdba.georgetown.edu/Comp/Derechos/salud.html>. Acesso em: 26 mar. 2009.

BASE de Datos Políticos de las Américas. (2006) Seguridad, Prevision y Asistencia Social. Estudio Constitucional Comparativo. [Internet]. Centro de Estudios Latinoamericanos, Escuela de Servicio Exterior, Universidad de Georgetown. En: <http://pdba.georgetown.edu/Comp/Derechos/seguridad.html>. Acesso em: 26 mar. 2009.

BOLíVIA. Constituição (1967). Constitución Política de la República de Bolivia. Con reformas de 1994, texto concordado de 1995, y reformas de 2002, 2004 y 2005. Disponível em: <http://pdba.georgetown.edu/Constitutions/Bolivia/ consboliv2005.html>. Acesso em: 26 mar. 2009.

BRASIL. Constituição (1988). Constituição da República Federativa do Brasil. Atualizada até a Emenda Constitucional n. 57, de 18 de dezembro de 2008. Disponível em: <http://www.planalto.gov.br/ccivil_03/constituicao/ Constituiçao_Compilado.htm>. Acesso em: 26 mar. 2009.

CHILE. Constituição (1980). Constitución Política de la República de Chile. Incluye Reformas de 1989, 1991, 1997, 1999, 2000, 2003 y 2005. Disponível em: <http://pdba.georgetown.edu/Constitutions/Chile/chile05.html>. Acesso em: 26 mar. 2009.

COLÔMBIA. Constituição (1991). Constitución Política de la República de Colombia. Incluye las reformas de 1993, 1995, 1996, 1997, 1999, 2000, 
2001, 2002, 2003, 2004 y 2005. Disponível em: <http://pdba.georgetown.edu/ Constitutions/Colombia/col91.html>. Acesso em: 26 mar. 2009.

COMPARATO, Fábio Konder. Ética: direito, moral e religião no mundo moderno. São Paulo: Companhia das Letras, 2006.

COSTA RICA. Constituição (1949). Constitucion Politica de la Republica de Costa Rica. Incluye Reformas de 1954, 1956, 1957, 1958, 1959, 1961, 1963, 1965, 1968, 1969, 1971, 1975, 1977, 1981, 1982, 1984, 1987, 1989, 1993, 1994, 1995, 1996, 1997, 1999, 2000, 2001, 2002 y 2003. Disponível em: <http://pdba.georgetown.edu/Constitutions/Costa/costa2.html>. Acesso em: 26 mar. 2009.

CUBA. Constituição (1976). Constitución Política de la República de Cuba. Actualizada hasta la Ley de Reforma Constitucional 2002. Disponível em: $<$ http://pdba.georgetown.edu/Constitutions/Cuba/cuba2002.html>. Acesso em: 26 mar. 2009.

DALLARI, Sueli Gandolfi. Book reviews: el derecho a la salud em las Americas: estudio constitucional comparado. Revista de Saúde Pública, São Paulo, v. 22, n. 4, p. 327-334, 1998.

DALLARI, Sueli Gandolfi. Uma nova disciplina: o direito sanitário. Revista de Saúde Pública, São Paulo, v. 22, n. 4, 1988. pp. 327-334. Disponível em: <http://www.scielo.br/pdf/rsp/v22n4/08.pdf>. Acesso em: 30 mar. 2009.

DUGUIT, León. Fundamentos do direito. São Paulo: Ícone, 2006. (Coleção Fundamentos do Direito).

EL SALVADOR. Constituição (1983). Constitucion de la Republica de El Salvador. Con reformas hasta 15 de octubre del 2003 incluídas. Disponível em: <http://pdba.georgetown.edu/Constitutions/EISal/constitucion2003.pdf>. Acesso em: 26 mar. 2009.

EQUADOR. Constituição (2008). Constitución de la República del Ecuador. Disponível em: <http://pdba.georgetown.edu/Constitutions/Ecuador/ ecuador08.html\#mozTocld273089>. Acesso em: 26 mar. 2009.

Fuenzalida-Puelma, Hérma L; Connor, Susan S. El derecho a la salud em las Americas: estudio constitucional comparado. Washington: Organización Panamericana de la Salud, 1989.

GUATEMALA. Constituição (1985). Constitucion Politica de la Republica de Guatemala. Reformada por Acuerdo Legislativo No. 18-93 del 17 de Noviembre de 1993. Disponível em: <http://pdba.georgetown.edu/ Constitutions/Guate/guate93.html>. Acesso em: 26 mar. 2009.

HOLANDA, Aurélio Buarque de. Bem público. In: Novo dicionário Aurélio da língua portuguesa. 3. ed. rev. e atual. São Paulo: Ed. Positivo, 2004. HONDURAS. Constituição (1982). Constitucion Politica de la Republica de Honduras. Incluye Reformas de 1982, 1984, 1985, 1986, 1987, 1988, 1989, 
1990, 1991, 1993, 1994, 1995, 1996, 1997, 1998, 1999, 2000, 2001, 2002, 2003, 2004 y 2005. Disponível em: <http://pdba.georgetown.edu/Constitutions/ Honduras/hond05.html>. Acesso em: 26 mar. 2009.

MAINETTI, José Alberto; PÉREZ, Marta Lucía. Referenciais de bioética en Argentina. In: PESSINI, Leo et al. (Coord.). Perspectivas de la bioética en Iberoamérica. Chile: OPS/OMS, 2007. p. 71-75.

MANUAL de direito sanitário com enfoque em vigilância sanitária: Ministério da Saúde, 2006. (Série E. Legislação de Saúde).

MERHY, Emerson Elias. Fórum Social Mundial e a Saúde: por uma ética global da vida. Interface, Botucatu, v. 6, n. 11, Aug. 2002. Disponível em: <http://www.scielo.br/ scielo.php?script=sci_arttext\&pid=S141432832002000200016\&lng=en\&nrm=iso > . Acesso em: 06 de out. 2009.

MEXICO. Constituição (1917). Constitución Política de los Estados Unidos Mexicanos. Con las reformas de 1993, 1999, 2000 y 2008. Disponível em: $<$ http://pdba.georgetown.edu/Constitutions/Mexico/textovigente2008.pdf>. Acesso em: 26 mar. 2009.

MOULIN, Madeleine. Saúde (Direito à). In: HOTTOIS, Gilbert; MISSA, JeanNöel (Org.) Nova enciclopédia de bioética: medicina, ambiente e tecnologia. Tradução: Maria Carvalho. Portugal: Instituto Piaget, 2003. (Coleção Medicina e Saúde).

NICARAGUA. Constituição (1987). Constitución Política de la República de Nicaragua. Con las reformas de 1995, 2000 y 2005. Disponível em: <http:// pdba.georgetown.edu/Constitutions/Nica/nica05.html>. Acesso em: 26 mar. 2009.

OMS. UNICEF. Declaração de Alma-Ata. 1978. Disponível em: < http:// www.opas.org.br/coletiva/uploadArq/Alma-Ata.pdf>. Acesso em: 25 mar. 2009.

ONU. Declaração Universal dos Direitos Humanos. 1948. Disponível em: $<$ http://www.onu-brasil.org.br/documentos_direitoshumanos.php $>$. Acesso em: 27 mar. 2009.

PANAMÁ. Constituição (1972). Constitución Política de la República de Panamá. Reformada por los Actos Reformatorios N. 1 y N. 2 de 5 y 25 de octubre de 1978, respectivamente; por el Acto Constitucional aprobado el 24 de abril de 1983; por los Actos Legislativos N. 1 de 1993 y N. 2 de 1994; y por el Acto Legislativo N. 1 de 2004. Disponível em: <http://pdba.georgetown.edu/ Constitutions/Panama/constitucion2004.pdf>. Acesso em: 26 mar. 2009.

PARAGUAI. Constituição (1992). Constitución Política de la República de Paraguay. Disponível em: <http://pdba.georgetown.edu/Constitutions/ Paraguay/para1992.html>. Acesso em: 26 mar. 2009.

PERU. Constituição (1993). Constitución Política del Peru. Con las reformas de 1995, 2000, 2002, 2004 y 2005 (hasta octubre). Disponível em: <http:// pdba.georgetown.edu/Constitutions/Peru/per93reforms05.html>. Acesso em: 26 mar. 2009. 
REPÚBLICA DOMINICANA. Constituição (2002). Constitucion Politica de la Republica Dominicana. Disponível em: < http://pdba.georgetown.edu/Constitutions/ DomRep/domrep02.html>. Acesso em: 26 mar. 2009.

SEGRE, Marcos; FERRAZ, Flávio Carvalho. O conceito de saúde. Revista de Saúde Pública, São Paulo, v. 31, n. 5, p. 538-542, 1997. Disponível em: <http:/ /www.scielo.br/pdf/rsp/v31n5/2334.pdf>. Acesso em: 27 mar. 2009.

SILVA, José Afonso da. Curso de direito constitucional positivo. 24. ed. rev. e atual. São Paulo: Malheiros Ed., 2005.

UNESCO. Declaração Universal de Bioética e Direitos Humanos. 2005. Tradução de: Ana Tapajós e Mauro Machado do Prado. Disponível em: <http:// www.bioetica.catedraunesco.unb.br/htm/X\%20-\%20htm/documentos/ declaracaojulho2006.pdf>. Acesso em: 23 abr. 2009.

URUGUAI. Constituição (1967). Constitución Política de la República Oriental del Uruguay. Incluye reformas plebiscitadas el 26 de Noviembre de 1989; 26 de Noviembre de 1994; 8 de Diciembre de 1996 y 31 de Octubre de 2004. Disponível em: <http://pdba.georgetown.edu/Constitutions/Uruguay/uruguay04.html>. Acesso em: 26 mar. 2009.

VENEZUELA. Constituição (1999). Constitución de la República Bolivariana de Venezuela. Disponível em: <http://pdba.georgetown.edu/Constitutions/Venezuela/ venezuela.html>. Acesso em: 26 mar. 2009.

WEIS, Carlos. Direitos humanos contemporâneos. 1. ed. São Paulo: Malheiros Ed., 2006. p. 27-28. 